by budding or grafting. Moreover, there is a very complete graded series, ranging from the case in which perfect harmony apparently exists between the two individuals, to that in which they are quite incompatible and no growth at all takes place. It may be, for example, that the dwarfing influence of certain stocks upon scions is the result of incomplete harmony. The phenomenon is more distinct in the case of stocks sometimes used for pears, upon which some varieties will grow perfectly satisfactorily for one or even two years, after which growth ceases and the plant eventually dies. A slightly different aspect of the matter may be observed in the case of plums, in which it is a matter of difficulty to induce the budded scion of some varieties to grow at all on certain stocks, and it should be emphasised that success depends upon both stock and scion. Whilst a variety which does not 'take' well on one stock grows quite satisfactorily on another, at the same time a stock which is unsuitable for one scion proves a good 'mother' to others.

It has been established at this Station that even seedlings which are closely related may vary considerably in their capacity to unite with a scion. The seedling Myrobolan plum stocks of commerce are an example of this variation. One Myrobolan seedling, for example, gives 95 per cent. success with buds of Czar plum, whilst another from the same batch gives less than 50 per cent. of satisfactory unions with the same variety: A similar range of variation exists within single groups of seedling stocks used for peaches; for example, the S. Julien group.

The problem is somewhat complex physiologically, and at present it is not even possible to state it accurately, although observations are now accumulating to this end.

From a practical point of view, there are two possibilities of circumventing the difficulty. Some pear varieties are incompatible with quince stocks, but a satisfactory tree is obtained by the process of ' double grafting' or 'intermediate grafting,' which involves grafting a compatible scion on the stock and regrafting the desired variety on the first scion a year later. There appears to be no reason why this method should not succeed with peaches.

A more certain method of avoiding the effects of incompatibility is to discover a stock which is suitable for the desired variety and to propagate that stock vegetatively. In this way the variation which is involved in the use of seedlings is obviated.

$$
\text { R. C. KNIGHT. }
$$

Ronald G. Hatton.

East Malling Research Station,

East Malling, Kent, August I7.

THE ill effect which often follows the grafting of the peach on seedling stocks described by Dr. Grabham in NATURE, July I7, is very common in peach nurseries on the Western Frontier of India, especially when the peach is budded on the almond. In the summer of I9I9, a few weeks before our service in Baluchistan came to an end, we paid some attention to this matter, the results of which are published in the Indian Forester of December rgig. We found that the restricted growth which often follows budding was due to imperfect sap circulation caused by an abnormal amount of callus tissue at the point of union between the stock and scion. Analyses of the peach leaves of affected trees in September I9I9 showed that they contained less nitrogen, ash, phosphorus, lime, and potash, and much more starch, than normal leaves. Consequently root development was far below the average.

The trouble can be avoided (I) by ring budding the peach either on seedling peach or seedling almond stocks and (2) by destroying all weakly abnormal plants in the nursery before planting out. Ring budding is best done when the peach or almond seedlings are growing vigorously in the early summer. At this time a ring of bark, with one bud, is easily removed from the parent peach tree. This is placed in water and at once fitted on the cylinder of wood of the seedling stock, care being taken to push it well home and in contact all round with the living bark of the stock. Union is rapidly established and the peach bud begins to grow in about ten days.

The adoption of this method of propagation in Madeira, combined with the elimination of all abnormal plants in the nursery stage, would probably solve the difficulties described by Dr. Grabham.

AlBerT Howard.

GaBrielle L. C. Howard.

Institute of Plant Industry,

Indore, Central India, August 9.

\section{The Constitution of the Stars.}

ON the theory of radiative equilibrium of stellar interiors, as developed mainly by Eddington, the assumption appears to be implicit that the density, mean molecular weight, and other contingent properties of stellar material, vary in a continuous manner from the star's surface to its centre. This assumption appears questionable.

Considering for simplicity a star consisting entirely of like atoms, it would appear probable that with the removal of each successive electron from the atom, due to increase of temperature with depth, or at least with the removal of all the electrons constituting each successive quantum-shell, abrupt discontinuities of state would occur comparable, in a general sense, with the separation of atomic matter into its phases.

The recent confirmation by Adams of Eddington's prediction of an abnormally high density for the 'dark' companion of Sirius may be held to prove that an assemblage of 'atoms ' entirely 'stripped. of their electrons cannot result from a mere extrapolation of the laws of a perfect gas-or, for that matter, of any phase of atomic matter-to matter in this sub-atomic condition. Eddington's application of his theory of radiative equilibrium to stellar substance obeying the gas laws throughout makes the density at the centre of the star only 'fifty' times the mean density; it seems possible that 'fifty million' would be nearer the truth.

The suggestion is, then, that the central portion of every luminous star consists of 'stripped' atoms and electrons-or possibly in the earlier stages of its lifehistory at least of protons and electrons-surrounded by successive shells of atoms in various stages of association. As the density, so the pressure and temperature in the sub-atomic core of the star would be enormously higher than on the assumption of continuous variation, and, conjecturally, high enough to condition the building up of the more complex nuclei from the simpler, with the consequent conversion of mass into radiation.

The mean temperature, the effective temperature, and the absolute magnitude of the star would depend mainly on the mass of the central core, and would continually adjust themselves to its variation, so that stability would appear to be assured. But it is easily conceivable that for different stars the total mass may bear very different ratios to that of the central 